\title{
Psychological problems with learning mathematical disciplines at the economics faculties
}

\author{
Rustam Sh. Mardanov $^{1}$, Asiya Yu. Khasanova ${ }^{1}$, and Gulnara F. Kalganova ${ }^{1 \mathrm{a}}$ \\ ${ }^{1}$ Kazan (Volga region) Federal University, Institute of Management, Economics and Finance \\ Butlerov str., 4, Kazan, Russia
}

\begin{abstract}
The paper analyzes some of the psychological problems of the economic faculties' students arising in the course of study of mathematical disciplines. These problems are primarily related with the lack of students' awareness, misconception about the calculation methods in their future profession, low motivation and performance, math anxiety, etc. They make additional difficulties which impede successful mastering of sophisticated material. Based on the experience of mathematical disciplines teaching, the paper provides some possible solutions to these problems with the lecturer who has to play an important role. The lecturer should orientate students towards serious and profound knowledge of economic and mathematical methods, create conditions for students' active participation in the educational process and provide them with comprehensive assistance in overcoming difficulties.
\end{abstract}

\section{Introduction}

Nowadays it is difficult to imagine the area of human activity where calculations made by mathematical methods do not penetrate into. This is most clearly evident in the economic sphere. Exact calculations allow having an adequate idea of the processes and trends occurring in economy and society, to carry out economic and mathematical analysis, and on this basis to draw correct conclusions. For example, based on differential calculus one can accurately determine the optimal output minimizing the marginal cost; calculations in the financial and banking practices are performed by using financial mathematics-based methods; economic forecasts cannot be done without stochastic mathematics, etc. [6]. Owing to mathematical programming methods one can find the optimal plan of resources allocation that maximizes the profits of the enterprise. That is why mathematical literacy is an essential attribute of highly qualified economist, and hence the teaching of mathematical disciplines at the Economics faculties of HEIs should be given serious consideration.

\footnotetext{
a Corresponding author: gkalganova@yandex.ru
} 
However, mathematical sciences are the most sophisticated subjects, and math achievement is very crucial issue for university students. It is obvious that mathematical thinking is not peculiar to all students. In this regard, while studying the mathematical disciplines the students deal with some psychological problems. The latter are interdependent with cognitive approaches that outline such facets as beliefs, attitudes, emotions, confidence, self-concept, mathematic anxiety, learned helplessness, motivation, etc. [2].

We confirm that psychological problems are expressed in the form of misrepresentation of the role of mathematical disciplines in university, anxiety of tests and exams in mathematics, as well as a negative attitude towards the study of mathematical disciplines. The main of them is the math anxiety. On the one hand, it is connected with the persistent feeling of tension, apprehension, and fears about performing math, and, on the other hand, is associated with poor math performance and achievement [1].

\section{Methodology}

This paper is based on the method of applied sociological research. The investigation purpose is to determine psychological math learning difficulties and offer some solutions for their overcoming.

A survey of students of the Institute of Management, Economics and Finance has been made up and conducted. The first year students (100 from 541 as respondents) participated in the inquiry. We set the task for the students to assess their mathematics performance (on the pre-university and university levels), attitude to future specialty and mathematical methods in it, frame of mind towards role of lecturer, methods of study, and selfindependent work in educational process. A set of questions concerned psychological items, math anxiety and ways of transcending the barriers emerged. Additional interest was manifested for using high-tech devices in cheating in exams. The latter is an increasing problem at schools and higher education establishments

\section{Main problems and findings}

One of the problem, we think, is primarily due to that a part of students have got primitive idea of the Economic University as an educational institution where deep knowledge of mathematics does not require. Many high school graduates believe that for financier it is enough to perform literally four arithmetic operations, such as addition, subtraction, multiplication and division. Part of them didn't expect they would have to study mathematical analysis, theory of probability, mathematical statistics, economic and mathematical methods, and so on. $31 \%$ of respondents said that they were really disappointed to find out what subjects they need to study, and $14 \%$ of respondents were undecided.

This frustration leads to negative emotions, which, in turn, create an unfavorable emotional background in student's attitude to disciplines of study. Such student reasons something like this: "I'm going to become an economist, not a mathematician, indeed. That's why I need to study higher mathematics?" Internal protest creates additional difficulties in the perception and understanding of the subject.

Another psychological problem appeared due to insufficient training of school leavers that is particularly reflected in mastering mathematical disciplines at the university. When asked if their preliminary training in mathematics is sufficient for the successful study, $36 \%$ of respondents answered affirmatively, $12 \%$ answered in the negative, the remaining $52 \%$ doubted. On the one hand, this is due to the fact that not all families give due attention to 
mental development of their children. On the other hand, in some schools teachers prefer to prepare their graduates for the state exam drilling them on the decision of the examination questions rather than giving deep knowledge. This position was supported by $56 \%$ of respondents' answers. Lack of preparation is the cause of misunderstanding the basics of mathematical sciences which leads to stress, fear before a test or exam, and, in consequence, decrease in immunity and diseases. Thus, a vicious circle emerges, and not every student can step out of it.

The table 1 provides information about the progress of mathematical disciplines. Math assessment data in the secondary school, which are listed in the top line, obtained from the respondents themselves. The bottom line shows the results of continuous assessment of the same respondents by lecturer during the first year of the University.

Table 1. Progress of mathematical disciplines

\begin{tabular}{lllll}
\hline Levels of assessment & Poor & Satisfactory & Good & Excellent \\
\hline at school & - & $21 \%$ & $41 \%$ & $38 \%$ \\
at the university & $16 \%$ & $39 \%$ & $24 \%$ & $21 \%$ \\
\hline
\end{tabular}

There is a clear decrease in the university's level of knowledge in math versus school's level. The students explain this situation by saying that at school one theme was being studied during several lessons, but at the University within one lecture they have a significantly greater amount of information. Therefore, in accordance with discipline's programs more time is given for independent work. However, not all students are able to comprehend the mathematical sciences independently. So, on the question "Is it possible to master mathematical subjects well without teacher's explaining?" 52\% of respondents answered that it was impossible, $39 \%$ of respondents believe that it is very difficult, and only $9 \%$ answered positively.

One reason for the decrease in math performance is that only $26 \%$ of respondents live in Kazan with their parents and less burden with everyday problems, while the remaining $74 \%$ of students came from other regions. They went out from under parental control and are forced to organize their life independently without direct assistance of their parents.

In accordance with the mathematical discipline a student has to allocate on an average 6 hours per week for independent work. However, not all students are paying enough attention to this activity. Table 2 shows the time that respondents assign to extracurricular study of mathematical disciplines.

Table 2. the time that respondents assign to extracurricular study of mathematical disciplines

\begin{tabular}{llllllll}
\hline Hours allotted for independent work per week & 0 & 1 & 2 & 3 & 4 & 5 & 6 \\
Number of students & 3 & 7 & 25 & 34 & 22 & 6 & 3
\end{tabular}

It is evident that only $3 \%$ of respondents allot sufficient time for independent study of mathematics, and the same number of students (3\%) generally ignores independent work in mathematics. On the average independent work amounts 2.95 hours per week.

As for psychological problems respondents indicated the following ones that hinder the successful study of mathematical disciplines (multiple answer questions): the fear of a complex subject (46\%); lack of understanding some topics (42\%); a negative attitude to the subject $(18 \%)$; a negative attitude to the lecturer $(16 \%)$; lightweight attitude towards mathematical disciplines (14\%). At the same time $33 \%$ of respondents expressed in favor of liberal and undemanding lecturer.

Commercialization of education plays negative role in the psychological problems too. Part of students who study on a fee basis and their parents do not understand that tuition fees gives them only the right to receive quality knowledge, but not the guarantee of their learning's highest ratings. They mistakenly believe that, by paying for tuition, they secure 
their right to get a higher education diploma and do not make any serious effort to "earn" this diploma. As a result, their knowledge is fairly mediocre and sometimes unsatisfactory. In addition, to pay tuition some students are forced to earn money. They have no time to study, and the quality of their education suffers.

Moreover, in recent years a large part of today's youth has performed a reappraisal of values: the cult of knowledge is having replaced by the cult of money and is falling by the wayside. In their view, education is not the advantage of a person, but wealth and his financial well-being. That sort of students needs a diploma not as an indicator of their professional competence, but as a business card when applying for a job. Hence, it is a lack of students' motivation to achieve academic success [5].

Scientific and technological progress in recent decades such as the Internet, mobile phones, smartphones, tablets and other high-tech devices have greatly expanded capabilities of students in obtaining any information [3]. At the same time, the electronic media started to play a destructive role in the learning process. Wishing to receive high marks, some students use these electronic gadgets in cheating in exams and, relying entirely on them, do not bother themselves with serious study of the discipline. $22 \%$ of respondents admitted that during test papers or examinations they could have used of gadgets. But without them such students are unable to solve even simple tasks. $13 \%$ of respondents believe that accessibility of cribs and gadgets helps them to overcome math anxiety. One should note also that the appearance of new forms of telephone, computer or Internet dependence have a detrimental effect on the mental state of students.

At the Faculty of Economics of the University the mathematical disciplines are studied within two years of BSc degree. Psychologists claim that the ability to analyze in general is developing in the process of knowledge accumulation only by the third year, and the ability to synthesize - only by the fifth year of study. Thus, the study of mathematical disciplines occurs in the absence of these abilities which creates additional difficulties in their development. In this regard, the leading role of lecturer in the process of getting students' knowledge is increasing. Live communication with students during lectures and seminars gives the teacher the opportunity to focus their attention on the most important aspects of the subject, to identify shortcomings and gaps in their knowledge, to correct errors, to give the right direction in learning, to help students to analyze the object of study and synthesize the knowledge gained thereby enhancing the self-esteem of students. The latter plays a very important role in overcoming psychological problems in the study of mathematical disciplines. All that require the continuous improvement of discipline's teaching methods.

Another possible solution is enacting additional education. Being the constituent part of the Russian educational system, it enables the pairing mechanism of succession of general and professional educational programs and technologies, and facilitates extracurricular activities of students as they can shape the educational trajectory independently taking into account their needs, inclinations and interests [7].

Concerning mathematics anxiety, $63 \%$ of respondents said that they are afraid of examination or test papers in mathematical disciplines, notably $30 \%$ have a strong fear. Respondents suggested measures of overcoming anxiety as follows: elaborate preparations (50\%); accessibility of cribs and gadgets (13\%); working environment in the classroom and active participation of each student in problem solving discussion $(20 \%)$; liberal lecturer (11\%); interactive forms of lectures and seminars $(6 \%)$.

These data show that the majority of students have a correct understanding of how to overcome math anxiety (elaborate preparation, the working environment in the classroom, interactive forms of learning), and only $24 \%$ of students consider that the cause of their problems is in a strict lecturer not permitting the use of cribs and other gadgets during the tests and examinations. Most students understand that having armed with knowledge they 
can get rid of the fear before tests or exams, become more confident, and be less stressed, thereby enhancing their' self-esteem.

\section{Discussion and conclusion}

Having long-term experience in high school, we offer the following ways to solve the above problems.

- We believe it is necessary to conduct purposeful work on vocational orientation of school graduates - the future students of economics departments - by creating economic classes in schools and courses and widely covering key aspects of economist and financier professions. For the future applicants of the Faculty of Economics one should not be news about future mathematical disciplines and their difficulties. It is needed that they will be internally ready and open to work in this area.

- It is necessary to continuously and steadily improve students' motivation towards study the mathematical disciplines. To this end, in our opinion, at each lecture and especially at practical classes so far as possible one must use problem-solving tasks by mathematical and other active learning methods that are directly related to the economics and finance [8 and 9]. These methods can be used to solve various issues, and in the power of teacher to choose problems which would cause keen students' interest.

- The important role in the vocational training is given to research work, attraction of talented students to work in mathematical circles, to participate in scientific conferences, and publication of their scientific works. Students' involvement in research activities by using of economic and mathematical methods will be an additional powerful incentive to more serious and deep study of mathematical disciplines and enrich their knowledge beyond the curriculum.

- If a student is not inclined to perception, the acquired information will pass by him leaving no visible trace in his mind. In the training both sides -the lecturer and the studentshould be active [10]. Knowledge is not just the information obtained from any field of science, but deep understanding the essence of the object of study and, if necessary, the ability to apply in a professional activity.

- The active involvement of students in the educational activity promotes the use by lecturer of interactive forms of classes such as debate, discussion of problematic situations, work in small groups with a clear division of responsibilities and subsequent result discussions, and so on [4]. During the lesson the lecturer must be a skilled conductor causing at students a continued interest in the subject of study and not leaving any student in the side of the matter of this discussion.

- Continuous monitoring of students' self-dependent studies by the lecturer, expanding the diversity of this individual work with compulsory analysis and its evaluation will lead students to understanding of the inevitability and the imminence of continuous and constant learning, make this work familiar to them. Armed with knowledge students can get rid of math anxiety, become more confident, and be less stressed.

- Increasing demands for students' knowledge on the part of lecturer, the strict prohibition of gadgets using during tests and exams will make students to get knowledge more seriously.

To sum it up, we believe that some psychological problems related to the study of mathematical disciplines at the university appear in school. We can conclude that attitudes towards mathematical disciplines, motivation and self-esteem of students, the ability to study and elaborate preparation can remove the above-mentioned difficulties. The role of lecturer in overcoming psychological problems, in our opinion, is to ensure a positive mental attitude of students in the classroom and independent work attracting students to the bilateral cooperation in the learning process. 


\section{References}

1. Beilock S.L., Ramirez G., On the interplay of emotion and cognitive control: implications for enhancing academic achievement. In J.P.Mestre \& B.H.Ross (Eds.). The Psychology of Learning and Motivation: Cognition in Education. Vol. 55, 137-169 (2011)

2. Belbase S., Images, anxieties, and attitudes toward mathematics. International Journal of Education in Mathematics, Science and Technology, 1(4), 230-237 (2013)

3. Curran K., Middleton G., Doherty C., Cheating in Exams with Technology. International Journal of Cyber Ethics in Education, 1(2), 54-62 (2011)

4. Derevenskaia O.Y., Active learning methods in environmental education of students. Procedia - Social and Behavioral Sciences. Vol. 131, 101-104 (2014)

5. Galishnikova E.M., Language learning motivation: a look at the additional program. Procedia - Social and Behavioral Sciences. Vol. 152, 1219-1224 (2014)

6. Mardanov R., Khasanova A., Issues of teaching mathematics in Economic faculties of Universities. Procedia - Social and Behavioral Sciences. Vol. 152, 1062-1065 (2014)

7. Mardanshina R., Zhuravleva E., Model of complementary linguistic education for economists. Procedia - Social and Behavioral Sciences. Vol. 152, 1091-1094 (2014)

8. Mingazova N.M., Modification of the active learning methods in Environmental education in Russian universities. Procedia - Social and Behavioral Sciences. Vol. 131, 85-89 (2014)

9. Palei T.F., Salakhatdinova L., The Study of the Phenomenon of Creativity in the Educational Environment. Procedia - Social and Behavioral Sciences, Vol. 131, 90-96 (2014)

10. Zalyaeva E. O., Solodkova I.M., Teacher-student Collaboration: Institute of Economics and Finance Kazan Federal University Approach. Procedia - Social and Behavioral Sciences. Vol. 152, 1039-1044 (2014) 